\title{
Genetic identification of populations of Bactrocera dorsalis (Diptera Tephritidae) in the Niayes and Lower Casamance areas in Senegal
}

\author{
Mariama. FAYE ${ }^{1 *}, 3$, Awa NDIAYE2,3, Ibrahima. DIALLO1,3 and Pape Mbacké SEMBENE ${ }^{1,3}$ \\ 1 Department of Animal Biology , Faculties of Sciences and Technics, Cheikh Anta Diop University of Dakar, Post box \\ 5005, Dakar Fann, Senegal \\ ${ }^{2}$ Center for the Development of Horticulture / Senegalese Institute for Research Agricoles / (ISRA / CDH), hydrocarbons \\ Road, Bel Air, Post box 3120 Dakar- Senegal \\ ${ }^{3}$ Genetics and Population Management (GENGESPOP) \\ ${ }^{*}$ Corresponding author e-mail: fayechantal1@gmail.com
}

Original submitted in on 21st December 2020. Published online at www.m.elewa.org/journals/ on 28 th February 2021 https://doi.org/10.35759/JABs.158.9

\begin{abstract}
Objectives: the study examines the effect of the host plant and of the agro-ecological area on the genetic structure of populations of Bactrocera dorsalis in order to apprehend an appropriate period to fight this pest. Methodology and results: this study was conducted in two large areas mango productions Senegal (area Niayes and the forest area South) on 41 individuals of Bactrocera dorsalis with mitochondrial gene sequencing (cytochrome B). Several haplotypes (28) of which 27 individual have been identified with a high level of genetic diversity ( $\mathrm{Hd} 0.972$ and Pi 0.1563). The genetic demo tests suggested a population in equilibrium, a moderate expansion and a grouping according to the areas thus revealing a genetic structure linked to the localities. In addition, the haplotype network showed a majority haplotype comprising all areas, 24 individual haplotypes and a typical haplotype to Notto.

Conclusion and application of findings : this exploratory study was in addition to having provided information on the genetic characterization of the species Bactrocera dorsalis , describes its structure and its genetic differentiation based on two areas - ecological where mango is practically cultivated in Senegal . It helped to understand the genetic identity card of the species Bactrocera dorsalis, whose purpose will be to know its weakest link and food preferences to provide alternative struggles.
\end{abstract}

Keywords: Bactrocera dorsalis, Niayes, lower Casamance, mangoes, citrus, PCR, sequencing, cytochrome B

\section{INTRODUCTION}

In Senegal, along with citrus fruits, mango represents a very important part of horticultural production (60 and $24 \%$ respectively) (Ndiaye et al., 2012). However, this production has faced many challenges of a phytosanitary nature and in recent years more particularly various phytophagous pests including the oriental fruit fly Bactrocera dorsalis (Hendel, 1912) (Diptera : Tephritidae) . These pests are responsible for significant damage causing losses estimated between 40 and $60 \%$ in the Niayes and 70 to $80 \%$ in Casamance (Grechi et al., 2013) and are also considered as a quarantine pest, which constitutes a brake on the export of various horticultural products (Norrbom, 2004). Since its appearance in Senegal (Vayssières et al., 2004), a number of questions have been asked about the 
structuring and genetic characterization of populations according to these plant hosts (mango, citrus fruits, etc.). Studies have clearly shown the impact of the food source of the genetic structure of population in insects (Sembene, 2000; Ndiaye, 2014) so it is therefore useful to consider the impact of the host plant and the agro-ecological area on the genetic structure of populations of this polyphagous pest. The genetic identification of populations of Bactrocera dorsalis and their characterization using molecular markers would be useful to provide answers concerning their evolutionary and

\section{MATERIAL AND METHOD}

Sampling: This study was carried out in ten orchards located in the two main agro-ecological areas of horticultural production in Senegal (fig 1): The Niayes area located along the northern Senegalese coast, commonly known as the big coast, extends from Dakar to Saint-Louis, in a strip $180 \mathrm{~km}$ long and 5 to $30 \mathrm{~km}$ wide). Administratively, it covers part of the regions of Saint-Louis and Louga, the departments of Tivaouane and Thiès and the entire region of Dakar. Geomorphologically, the Niayes are sandy and are made up of a series of dunes that alternate with interdune basins (Fall et al., 2001). Part of this area was sampled, it is the orchards of Sébikotane $\left(14^{\circ} 44^{\prime} 49^{\prime \prime}\right.$ North and $17^{\circ} 08^{\prime} 12^{\prime \prime}$ West), Keur Moussa located about fifty kilometres (Km) from Dakar (14 $46^{\circ}$ ' 53 "North and $17^{\circ} 06^{\prime} 41^{\prime \prime}$ West), from Pout, a town of Thiès located 54 $\mathrm{km}$ east of Dakar towards the altitudes $\left(14^{\circ} 46^{\prime} 26^{\prime \prime}\right.$ North and $17^{\circ} 03^{\prime} 37^{\prime \prime}$ West), and from Notto a village located $23 \mathrm{~km}$ from Thiès $\left(14^{\circ} 58^{\prime} 56^{\prime \prime}\right.$ North and $17^{\circ} 00^{\prime} 55^{\prime \prime}$ West). The southern forest area, part of the lower Casamance in the Ziguinchor region (towards altitudes $12^{\circ} 33^{\prime}$ North and $16^{\circ} 16^{\prime}$ West) which borders the Casamance river thus forming the border with Gambia in the North and in the South by the Guinea Bissau. It represents an area of $7339 \mathrm{~km}^{2}$ of the national territory. The region is influenced by a sub-Guinean climate, phylogenetic history. This would allow it possible to define adequate strategies of struggles against this polyphagous pest of mangoes and citrus fruits by the differentiation of its populations. This study aims to know the structuring effect of the host plant and agro-ecological area on the populations of $B$. dorsalis. More specifically, it is about determining the polymorphism of populations of $B$. dorsalis, the diversity and genetic structure of populations depending on host plants and localities, but also to assess the demographic evolution of populations of B. dorsalis.

which favours a high rainfall compared to the central and northern regions of the country. Seven localities of this city (Bandjikaky, Thionck-Essil, Dianna, Boudialabou, Djitoth, Mlomp-Essyl, and Mouhamouda Diola) were the subject of our sampling plan during this study. Sampling was carried out by collecting infested citrus fruits from the aforementioned orchards. These fruits, once in the laboratory are incubated in buckets lined with sand. At the end of the third instar larvae, the larvae extricate themselves from the fruit and collect in the sand, which is sieved to collect the pupae. These are then placed in petri dishes and the adults are systematically recovered. They are then kept in $90^{\circ}$ alcohol to be used for genetic manipulation. In total, 41 individuals were collected, including 27 from the Niayes area and 14 from the South forest area (Casamance).

$>$ Niayes area

- 11 individuals / Grapefruits

- 8 individuals / Mandarin

- 8 individuals / Orange

$>$ South forest area

- 6 individuals / Pomelos

- 3 individuals / Mandarin

- 5 individuals / Orange 


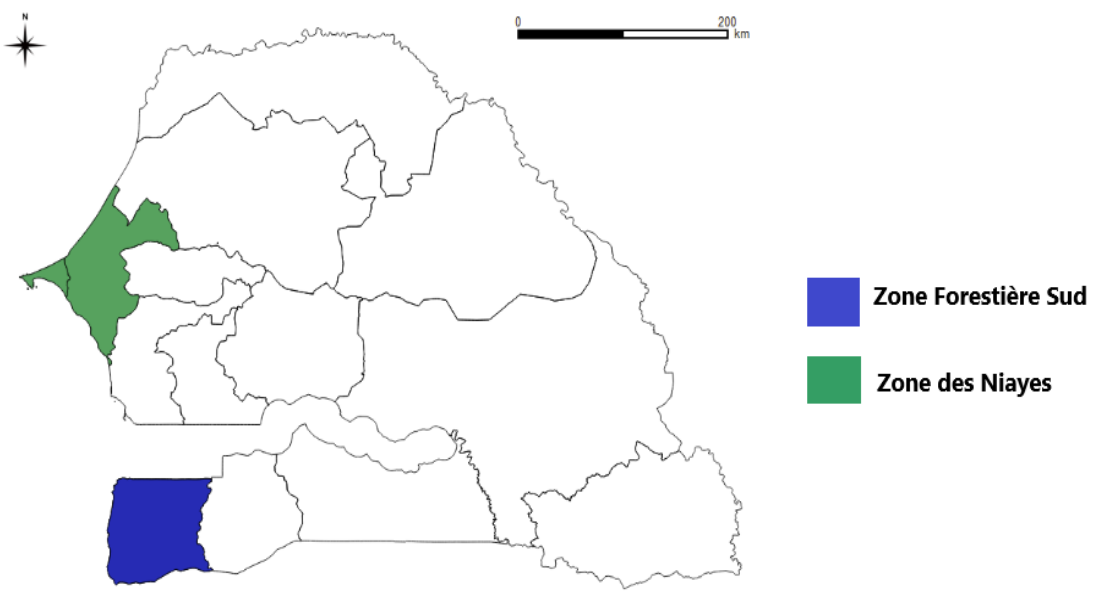

Fig 1: Representative map of the two agro-ecological areas of Senegal built with QGIS version

DNA extraction: Total DNA from each fly sample was extracted following a specific extraction protocol. Each fly devoid of an abdomen is ground in $200 \mu$ l of T1 buffer containing $1 \mathrm{M}$ tris $\mathrm{HCl}$ preventing the degradation of DNA, 0.5 M EDTA which is a chelator of bivalent ions, sucrose and distilled water. The Eppendorf tubes are placed in a water bath for 15 minutes. After recovery, the tubes are centrifuged at $1256.6370 \mathrm{rad} / \mathrm{s}$ for 10 seconds at room temperature (AT) then $200 \mu$ of $T 1$ bis buffer containing proteinase $\mathrm{K}$ for the degradation of proteins are added and $0.5 \%$. SDS (detergent for destroying cell membranes, nucleus and dissociating DNA from proteins). The tubes are then incubated in the oven at 37 ${ }^{\circ} \mathrm{C}$. overnight. At this stage, after centrifugation to bring down the condensation, $50 \mu \mathrm{l}$ of T2 buffer $(8 \mathrm{M}$ potassium acetate ) are added for the precipitation of DNA and centrifuged at $1256.6370 \mathrm{rad} / \mathrm{s}$ (20 minutes, AT ) for then recover the supernatant in other Eppendorf tubes. The next step consists in mixing the supernatant with 2.5 volumes of absolute ethanol (for example for $400 \mu \mathrm{l}$ recovered, added $1000 \mu \mathrm{l}$ of ethanol) then left at RT for 5 minutes, centrifuge for 20 to 25 minutes at 1256 , $6370 \mathrm{rad} / \mathrm{s}(\mathrm{TA})$ then empty the ethanol. The supposed DNA is then eluted for 24 hours on a table with $T 3$ elution buffer containing only distilled water, $1 \mathrm{M}$ tris $\mathrm{HCl}$ and 0.5 $M$ EDTA . The quality of the DNA extracts was estimate by electrophoretic migration. The resulting DNA is then kept at a temperature lower at $20^{\circ} \mathrm{C}$.

Cytochrome $B$ amplification: The amplification of the sequence was carried out on a 96-well PCR plate with a reaction volume of $25 \mu \mathrm{l}$ containing $16.8 \mu \mathrm{l}$ of ultra-pure water, $2.5 \mu \mathrm{l}$ of the coloured $10 \mathrm{x}$ buffer, $1 \mu \mathrm{l}$ of $\mathrm{MgCl}_{2}$, $0.5 \mu \mathrm{l}$ of dNTPs, $1 \mu \mathrm{l}$ of each of the two primers (CB-J10933 (F): 5'-TAT GTA CTA CCA TGA GGA CAA ATA TC-3 'and CB-N-11367 (R): 5 '-ATT ACA CCT CCT AAT TTA TTA GGA AT-3'), $0.2 \mu \mathrm{l}$ of Taq polymerase and $2 \mu \mathrm{l}$ of DNA extract diluted to the tenth. The plate containing the products was then introduced into an Eppendorf type thermal cycler programmed with the following conditions: initial denaturation at $94^{\circ} \mathrm{C}$ for 3 minutes followed by 35 cycles of denaturation at $94^{\circ} \mathrm{C}$ for 1 minute, from hybridization to $47^{\circ} \mathrm{C}$ for 1 minute, an initial extension of the complementary DNA strand at $72^{\circ} \mathrm{C}$ for 1 minute, a final extension at $72^{\circ} \mathrm{C}$ for 10 minutes terminated by a hold at $10^{\circ} \mathrm{C}$ for the conservation of PCR products in the thermal cycler. Amplification is repeated twice in order to obtain a volume of $50 \mu$ for sequencing needs. The PCR products (DNA extracts or PCR products $+2 \mu \mathrm{l}$ of bromophenol blue) were separated in $1.5 \%$ agarose gel using TAE buffer and migrated at 100 Volt then visualized under UV after passage with Ethidium Bromide (BET).

Data analysis: DNA sequences were aligned using ClustalW program implemented in software BioEdit version 7.0.5.3 (Hall, 1990), verified manually based on the electropherograms. All the parameters of genetic diversity such as the number of haplotypes $(H)$, haplotypic diversity $(\mathrm{Hd})$, nucleotide diversity $(\mathrm{Pi})$, the mean number of nucleotide difference $(K)$ were revealed with DnaSp version 5.10 (Librado and Rosas, 2009). According to Grant and Bowen (1998), the levels of genetic diversity detected through the $\mathrm{Hd}$ and $\mathrm{Pi}$ indices 
are considered under conditions of rapid expansion if $\mathrm{Pi}$ $<0.5 \%$ and $\mathrm{Hd}>50 \%$, under conditions of divergence between geographically subdivided populations when $\mathrm{Pi}$ $>0.5 \%$ and $\mathrm{Hd}<50 \%$, under conditions of a stable population with a long evolutionary history or the result of a second contact of previously differentiated lines if $\mathrm{Pi}$ $>0.5 \%$ and $\mathrm{Hd}>50 \%$ and under the conditions of a recent bottleneck or founding effect starting from one or more lines when $\mathrm{Pi}<0.5 \%$ and $\mathrm{Hd}<50 \%$. The genetic distances were estimated with the Mega software version 7.0.14 (Tamura et al., 2016) and at two hierarchical levels:

- $\quad$ Area where individuals from the Niayes is been considered a population 1 (pop1) and those from the southern forest area (Casamance) as a population 2 (pop2).

- Host plants where the four populations have been designed according to the varieties of plants: mandarins (pop1), oranges (pop2), grapefruits (pop3) and pomelos (pop4).

The sequences were then analysed with Mega to obtain the genetic intra and inter population distances, the phylogenetic reconstructions with the methods of parsimony and likelihood. The parsimony method considers that a tree is optimal when its total length (number of steps necessary to explain the analysed data set) is minimal. The criterion information of Akaike (Akaike Information Criterion, AIC) was used to estimate

\section{RESULTS}

Polymorphism and genetic diversity: The analysis of the chromatograms of the 41 sequences obtained shows that only the 33 sequences were exploitable and carefully aligned with a homology of the sites without the best of molecular evolution model for the probabilistic method of maximum likelihood (model HasegawaKishino-Yano (HKY) plus gamma distribution $(G+I))$ to determine the evolutionary relationships. Empirical studies and by simulation have shown that maximum likelihood methods are currently the most efficient for finding the true phylogenetic tree (Lopez et al., 2002). The robustness of the nodes was evaluated for 1000 bootstrap repetitions. A complete sequence of the genome of Ceratitis capitata (Diptera) was used to root the phylogenetic trees. The samples were then subjected to a Analysis of molecular variance (AMOVA) inserted in the program of Arlequin version 3.5.1.3 (Excoffier and Lischer, 2010) in order to evaluate the genetic structure and genetic variability within between and populations of Bactrocera. dorsalis (Fst). The demographic history has been studied using the disparity distributions such as Tajima's D (1989) and Fu's Fs (1997), obtained by the program Arlequin and DnaSp to estimate population growth. The Rag indices (irregularity index) and SSD (squared sums of deviations) were also calculated in a similar way. To better understand demographic evolution and the relationships between haplotypes, a haplotype network was built with Network version 4.6.1.2 (Bandelt et al., 1999) where each circle represented a haplotype and the size of the circle was proportional to its frequency. The circles were coloured according to the sampling sites.

difficulty and with clearness on a total of 368 base pairs and without any insertion or deletion. The parameters of genetic diversity are presented in Table1.

Table 1: Polymorphism and Genetic Diversity

\begin{tabular}{ccccccc}
\hline Settings & H & HD & Sd & $\pi$ & Sd & k \\
\hline Niayes area & 18 & $0.984 \pm 0.00056$ & 0.024 & $0.208 \pm 0.00057$ & 0.02408 & 76.55 \\
\hline South area & 11 & $0.962 \pm 0.00246$ & 0.05 & $0.0515 \pm 0.00089$ & 0.02212 & 18.962 \\
\hline $\begin{array}{c}\text { Niayes } \mathrm{x} \\
\text { South }\end{array}$ & 28 & $0.972 \pm 0.0005$ & 0.022 & $0.1563 \pm 0.00057$ & 0.02388 & 57 \\
\hline
\end{tabular}

H: haplotypes, Hd: haplotype diversity, Sd: standard deviation, $\pi$ : nucleotide diversity, $\mathrm{K}$ : average number of nucleotide differences

Differentiation and genetic structuring: The intra and inter-population genetic distances $(D)$ as a function of the two agro-ecological areas (Niayes and South) and of the host plants (mandarin, grapefruit, orange and pomelo) are respectively summarized in Table 2 . The degrees of genetic differentiation (Fst) between areas and between varieties of host plants are detailed in the table of AMOVA analyses (Table 3) 
Table 2: Intra and inter-population genetic distances according to areas and host plants

\begin{tabular}{|c|c|c|c|c|c|}
\hline \multirow[t]{3}{*}{ Areas } & \multicolumn{5}{|c|}{ Genetic distances } \\
\hline & \multirow[t]{2}{*}{ Intra-population } & \multicolumn{4}{|c|}{ Inter-population } \\
\hline & & Niayes (pop1) & \multicolumn{3}{|c|}{ South (pop2) } \\
\hline Niayes (pop1) & $D=0.092 \pm 0.016$ & & & & \\
\hline South (pop2) & $D=0.011 \pm 0.004$ & \multicolumn{4}{|c|}{$D=0.012$} \\
\hline \multirow[t]{2}{*}{ Host plants } & \multirow[t]{2}{*}{ Intra-population } & \multicolumn{4}{|c|}{ Inter-population } \\
\hline & & Mandarin (pop1) & Oranges (pop2) & Grapefruits (pop3) & $\begin{array}{l}\text { Pomelos } \\
\text { (pop4) }\end{array}$ \\
\hline $\begin{array}{l}\text { Mandarins } \\
\text { (pop1) }\end{array}$ & $D=0.112 \pm 0.025$ & ---- & 0.018 & 0.018 & 0.018 \\
\hline $\begin{array}{l}\text { Oranges } \\
\text { (pop2) }\end{array}$ & $D=0.061 \pm 0.012$ & 0.095 & ---- & 0.008 & 0.010 \\
\hline $\begin{array}{l}\text { Grapefruits } \\
\text { (pop3) }\end{array}$ & $D=0.017 \pm 0.007$ & 0.078 & 0.038 & ---- & 0.009 \\
\hline $\begin{array}{l}\text { Pomelos } \\
\text { (pop4) }\end{array}$ & $D=0.051 \pm 0.013$ & 0.082 & 0.055 & 0.035 & ---- \\
\hline
\end{tabular}

Depending on the study areas, they vary between 0.011 (South) to 0.092 (Niayes) for intra-population distances and 0.012 for genetic inter-population distances. The Niayes area records a much higher intra-population genetic distance $(0.092)$ than the southern forest area (0.011). Depending on the host plants, a much greater intra-population genetic distance in absolute value was noted in mandarin (0.112) followed by oranges $(0.061)$, pomelos (0.051) and grapefruits (0.017). The interpopulation genetic distances were respectively higher in the orange, pomelo and grapefruit varieties coupled with the mandarin variety $(0.095 ; 0.082$ and 0.078$)$ and lower than those between populations: pop3 / pop2; pop4 / pop2 and pop4 / pop3 (0.008; 0.010 and 0.009).

Table 3: Summary of AMOVA analysis of different populations of $B$. dorsalis

\begin{tabular}{|c|c|c|c|c|c|c|}
\hline $\begin{array}{l}\text { Localities/Host } \\
\text { plants }\end{array}$ & $\begin{array}{l}\text { Source of } \\
\text { variation }\end{array}$ & df & $\begin{array}{l}\text { Sum } \\
\text { squares }\end{array}$ & $\begin{array}{l}\text { Variance } \\
\text { components }\end{array}$ & $\begin{array}{l}\text { Percentage of } \\
\text { variation }\end{array}$ & Fst \\
\hline \multirow{3}{*}{ Areas } & $\begin{array}{l}\text { Between } \\
\text { populations }\end{array}$ & 1 & 79.203 & $3.30458 \mathrm{Va}$ & 10.85 & Niayes $=0.08443$ \\
\hline & $\begin{array}{l}\text { Within } \\
\text { populations }\end{array}$ & 31 & 841,069 & $27.43585 \mathrm{Vb}$ & \multirow[t]{2}{*}{89.15} & South $=0.14572$ \\
\hline & Total & 32 & 920,273 & 30.43585 & & $\begin{array}{l}\text { Fst overal }=0,10858 \\
\text { Pvalue }=0.01662\end{array}$ \\
\hline \multirow{3}{*}{ Host plants } & $\begin{array}{l}\text { Between } \\
\text { populations }\end{array}$ & 3 & 97.103 & $0.48797 \mathrm{Va}$ & 1.69 & \multirow{3}{*}{$\begin{array}{l}\text { Mandarins }=-0.02479 \\
\text { Oranges }=0.02265 \\
\text { Grapefruits }=0.00741 \\
\text { Pomelos }=0.07968 \\
\text { Fst }_{\text {overall }}=0,01690 \\
\text { Pvalue }=0.2697\end{array}$} \\
\hline & $\begin{array}{l}\text { Within } \\
\text { populations }\end{array}$ & 29 & 823,169 & $28.38515 \mathrm{Vb}$ & \multirow[t]{2}{*}{98.31} & \\
\hline & Total & 32 & 920,273 & 28.87312 & & \\
\hline
\end{tabular}

Depending on the study areas, we note that $89.14 \%$ of the variation is due to variation within populations and that only $10.85 \%$ is due to variation between populations, which corresponds to an Fst overall of 0.10858 . Likewise, depending on the varieties of plants, $98.31 \%$ of the variation is due to variation within populations and $1.69 \%$.
Demographic evolution: Neutrality tests are carried out at two levels (area and host plants) in order to distinguish the nature of the mutations observed in the data set, assuming a priori that the mutations are neutral (Table 4). 
Faye M. et al., J. Appl. Biosci. 2021 Genetic identification of populations of Bactrocera dorsalis (Diptera Tephritidae) in the Niayes and Lower Casamance areas in Senegal

Table 4: Neutrality indices

\begin{tabular}{lcccc}
\hline $\begin{array}{c}\text { Localities / Host } \\
\text { plants }\end{array}$ & Tajima's D* & Fu's Fs & Rag & SSD \\
\cline { 2 - 5 } Agro-ecological area & -0.287 & 0.1114 & 0.01737 & 0.01286 \\
& Pvalue $=0.435$ & Pvalue $=0.509$ & Pvalue $=0.77800$ & $\begin{array}{c}\text { Pvalue }= \\
\end{array}$ \\
& & & & 0.77200 \\
\hline Host plants & -0.09624 & 1.35586 & 0.08107 & 0.05278 \\
& Pvalue $=0.47825$ & Pvalue $=0.58025$ & Pvalue $=0.63500$ & Pvalue $=$ \\
& & & & 0.56375 \\
\hline
\end{tabular}

Depending on the two agro - ecological areas and the host plants, the tajima's D and Fu's Fu are not significant at the $5 \%$ level. However, a negatively significant Tajima's $D$ was noted in the population of the South area $(-1.81858$ Pvalue $=0.015)$. The observed distributions and those expected of the pairwise nucleotide differences of cytochrome $b$ sequences of the populations of the two agro-ecological areas are shown in fig2. They indicate a multimodal distribution with a demographic signal of a population in moderate expansion with a non-superposition of the two curves (observed and expected). The mismatch analysis (Table 4) is associated with the two indices, SSD (sum of the squares of the deviations) and Rag (irregularity index) which are all-insignificant at the $5 \%$ level and test the goodness of fit of the distribution.

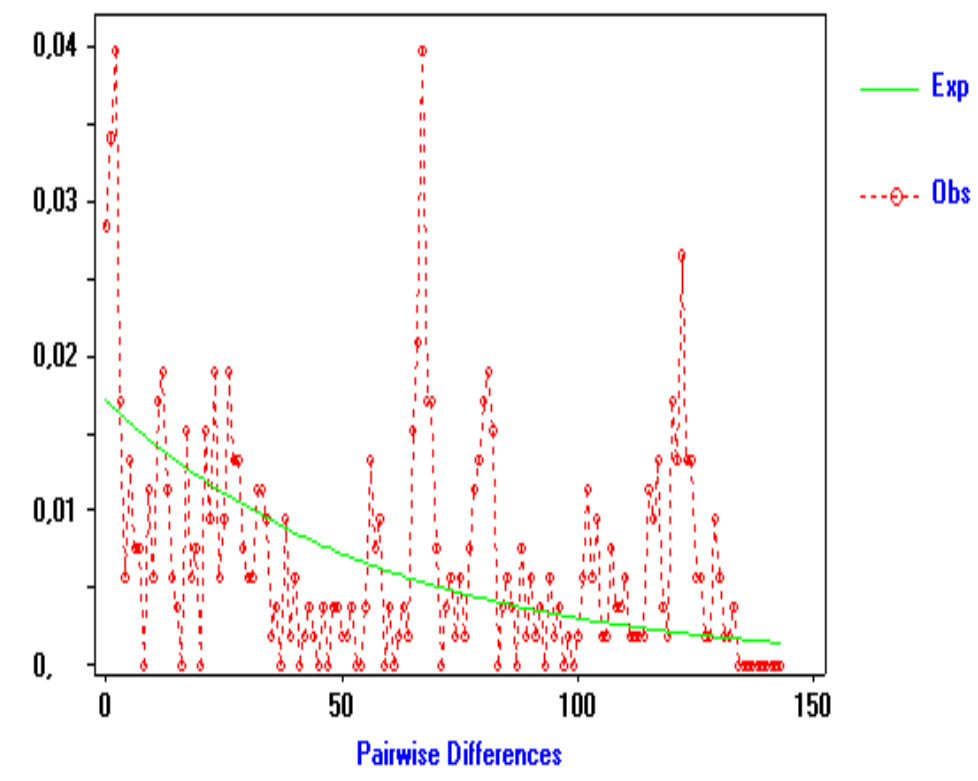

Fig 2: Observed distribution curve of the pairwise nucleotide differences of Cytochrome $b$ sequences in Bactrocera dorsalis of the populations of the two agro-ecological areas under a model of population expansion

Phylogenetic reconstructions: Phylogenetic trees by cladistics methods: maximum parsimony and likelihood are represented by the figures below (figure 3 and 4). 


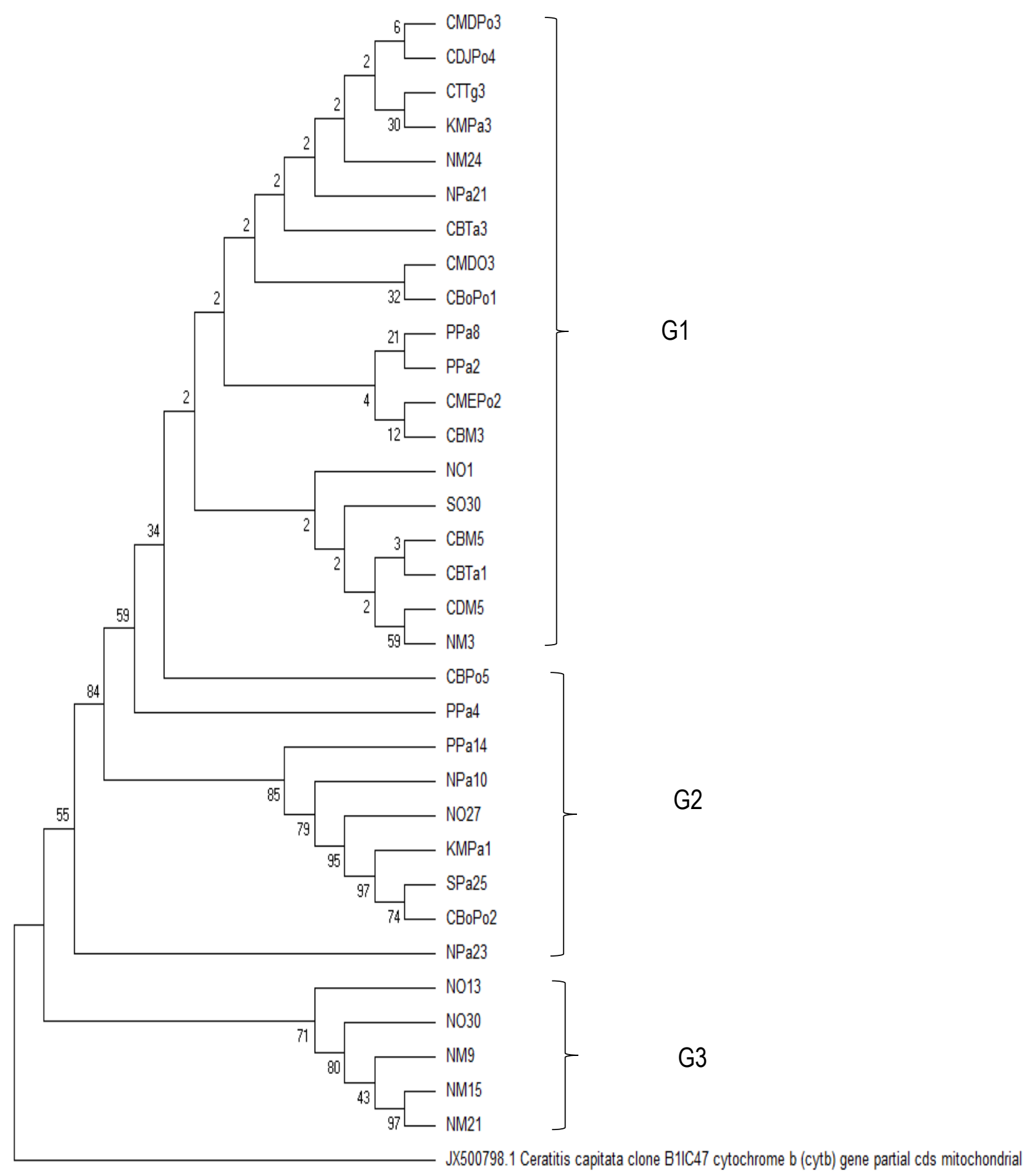

Fig 3: Topology of the consensus tree obtained from maximum parsimony for the portion of the Cytochrome $b$ gene with bootstrap. Ceratitis capitata is used as an out-group 


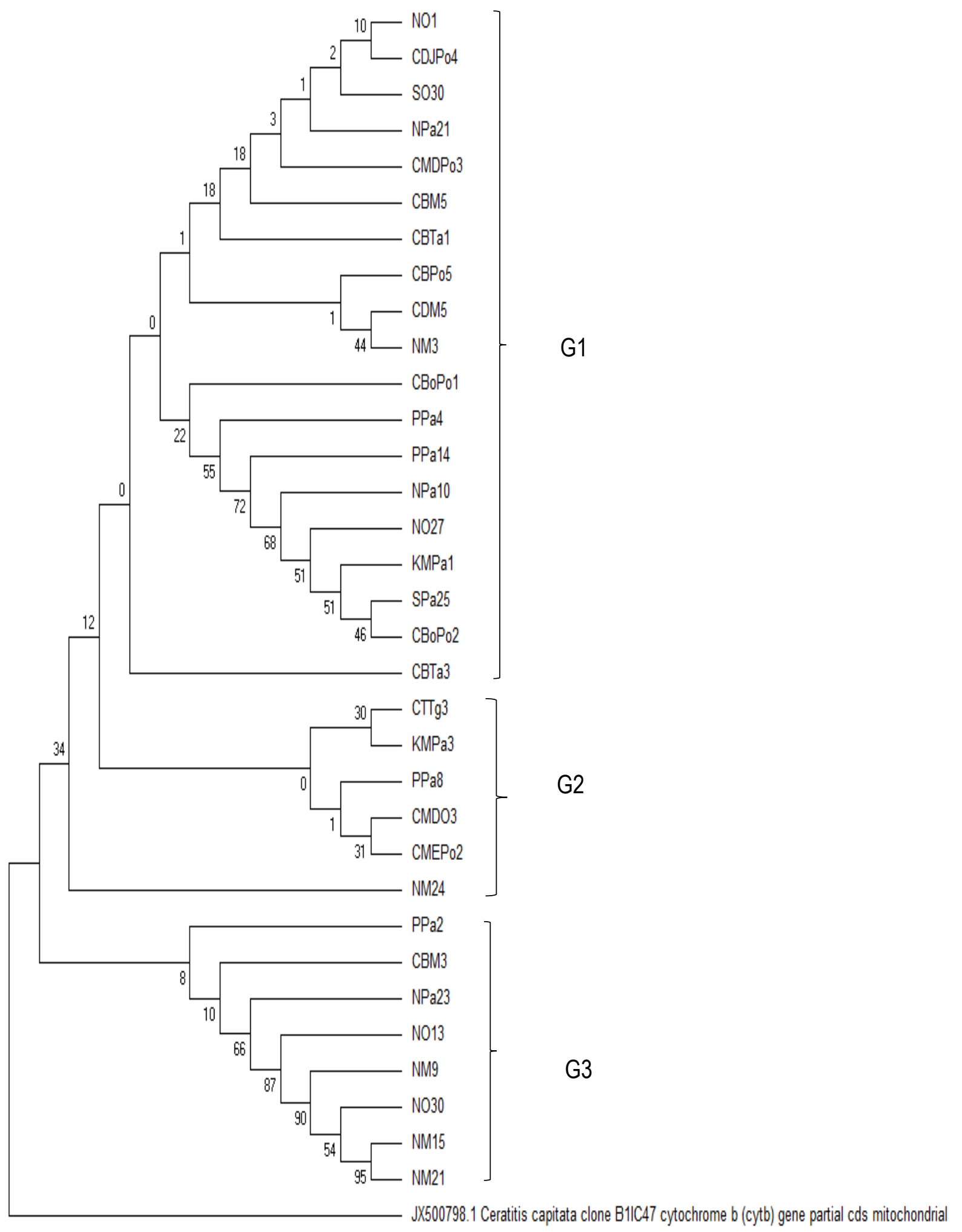

Fig 4: topology of the consensus tree obtained for maximum likelihood for the portion of the Cytochrome b gene with bootstrap. Ceratitis capitata is used as an out-group 
The phylogenetic trees (Figures 2 and 3 ) represented by the maximum parsimony (MP) and likelihood (ML) methods respectively present three distinct groups. Clade (G1) is made up of 11 individuals from the southern area and 8 from the Niayes area for the parsimony method (with all varieties of host plants). For the ML method, the G1 clade is made up of 19 individuals (including 9 from Casamance and 10 from the Niayes area) from all varieties. The G2 clades of the two phylogenetic reconstruction methods consist of individuals from the two study areas. Clade 3 for the maximum parsimony method is only composed of individuals from Niayes with the varieties of orange and mandarin and for the tree constructed with the likelihood method, clade 3 is mainly composed of individuals from the area Niayes partly from the Notto and Pout sites and a single individual from the South area (CBM3).

Haplotype network: Phylogenetic relationships among haplotypes presented by Figure 5 shows a majority central haplotype consisting of seven individuals whose (CBM5, CMDP03, NPa21, SO30, NO1, CDjPo4, CBTa1 and CBTa3) haplotype typical Notto and 24 haplotypes individual.
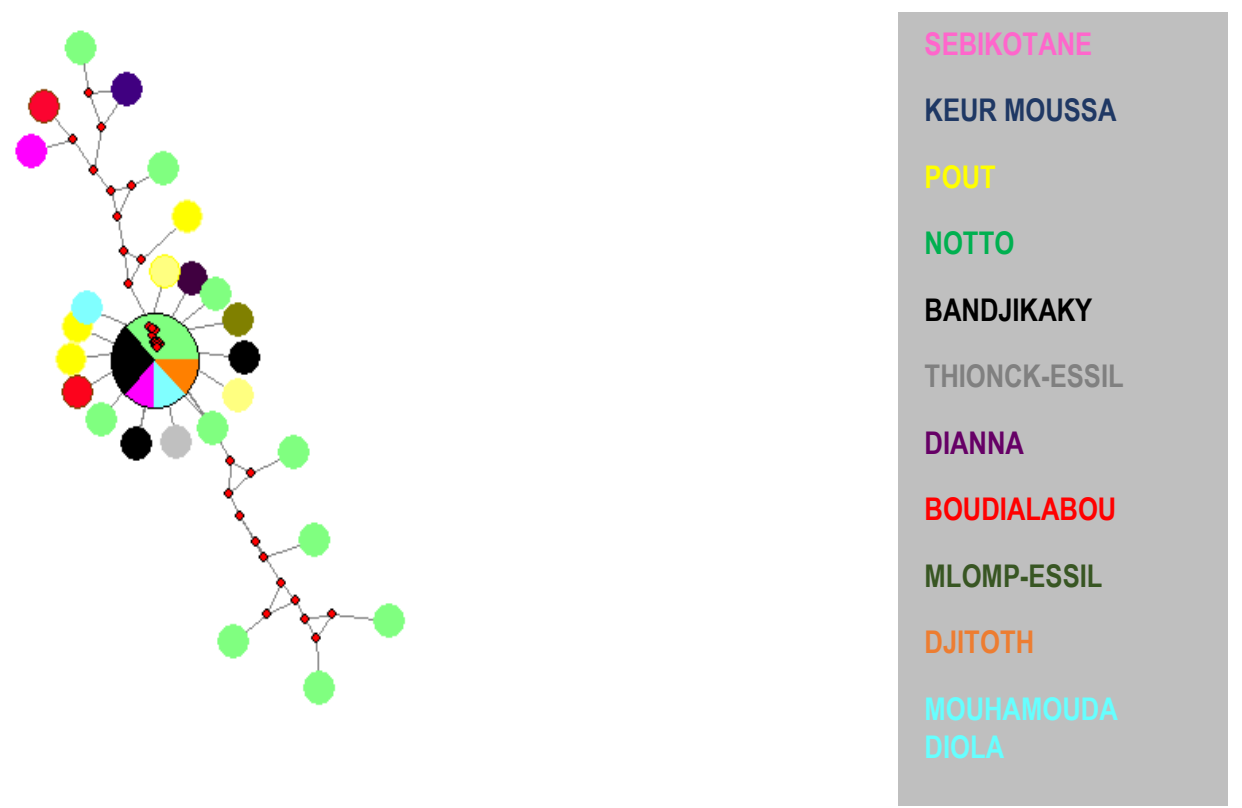

Figure 5: Haplotype network of the 33 individuals sampled based on the sequences of cytochrome b constructed with Network.

\section{DISCUSSION}

The general objective of this study is to know the effect of the host plant and of the agro-ecological area on the genetic structure of populations of $B$. dorsalis (Diptera, Tephritidae, a polyphagous pest infesting mangoes, oranges, citrus and others). The percentage of alignment of the 33 individuals is low for some and high for others. He thus suggests a strong genetic variability with a number of haplotypes of 28 for the 33 individuals including a haplotype $(\mathrm{H} 1)$ grouping together 6 individuals, 3 in each of the two areas, 17 individual haplotypes from the Niayes area and 10 from the lower Casamance. A higher number of haplotypes is found by the studies of Onah et al. (2017) on the Application of PCR-RFLP of COI Gene for Identification of Life Stages of Bactrocera dorsalis and Ceratitis anonae Infesting
Citrus in South-eastern Nigeria who had worked on a sample of 221 individuals including 143 haplotypes after analysis. The exploitation of the parameters of genetic diversity reveals to us for the two areas, a strong haplotypic diversity $\mathrm{Hd}(0.972)$ and a strong nucleotide diversity Pi (0.1563). This could correspond to a signal from a stable population with a long evolutionary history or the result of a second contact of previously differentiated lines according to Grant and Bowen (1998). However, the results of the AMOVA analyses showed that this genetic diversity is more noticed within populations than between populations, which corroborates the results of Shi et al. (2012), Qin et al. (2018) and Choudhary et al. (2016) who also mentioned a high level of genetic diversity within populations of $B$. 
dorsalis. The intra-population genetic distances in the two agro-ecological areas vary from 0.011 to 0.092 and from 0.012 to 0.061 for the inter-population distances. These inter-population distances results are comparable with those of Gasperi et al. (1991) which vary from 0.011 to 0.107 and from 0.026 to 0.028 in the two Mediterranean (Sardinia and Procida) and African populations of flies (Kenya and Reunion). However, according to the same author, genetic variability between populations (Sardinia, Procida, Kenya and Reunion) is not linked to variability within populations. Depending on the host plant, the intra-population distances vary from 0.017 to 0.112 therefore more variability and polymorphism on mandarins $(0.112)$ than on pomelos (0.051). Which would suggest a high level of genetic diversity within populations. For inter-population distances, we noticed the strongest genetic differentiation between the mandarin and grapefruit varieties and the small variability between the grapefruit and pomelo varieties. The degree of genetic differentiation between the two agro-ecological areas Fst (0.10858) observed during the molecular variance analysis (AMOVA) corresponding to $10.858 \%$ is greater than the Fst between varieties of plants $(1.69 \%)$, this which reveals a greater genetic variability between the two study areas than between the varieties of host plants. However, the percentage of variation is much more important within populations as well according to localities (89.14\%) as to host plants (98.31\%). This suggests that the genetic differentiation and the structuring of populations of $B$. dorsalis would be linked more to the agro-ecological area than to the varieties of plants. The results are in the same logic as those of Choudhary et al. (2016) who also reveal higher percentages of variation within populations than between populations of $B$. dorsalis respectively for the cox1 (78.83\%) and nad1 (92.90\%) genes. The Fst values compared with those of genetic distances and AMOVA analyses reaffirm the genetic variability observed within some of the populations. The neutrality indices show of tajima's $D$ evaluating the general deviation of the allele frequency spectrum significantly negative (-1.81858) and a Fu's Fs negative and nonsignificant of $(-0.35387)$ in the southern area, which indicates the possibility of a sudden and recent expansion of populations of $B$. dorsalis according to Choudhary et al. (2016). Indeed, a negative Tajima's D corresponds to an excessive number of alleles (a low frequency polymorphism), which would suggest a recent expansion of the population or a gene undergoing a genetic knock-on effect (bottleneck or a selective scanning) (Holsinger, 2010 and Zeng et al. 2006). In the Niayes area, the analysis of the neutrality tests shows a tajima's D and Fu's Fs not significant at the 5\% level, thus suggesting a population in demographic equilibrium or in moderate expansion. Studies by Shi et al. (2012) who, by combining mitochondrial markers with microsatellite markers, also made it possible to assess the level of genetic diversity of $B$. dorsalis, the structuring of populations but also to draw the conclusion on the model of sudden expansion. Likewise, a study conducted by Choudhary et al. (2018) on the genetic analysis of populations of $B$. zonata in India based on the cox1 and nad1 genes also reveals a sudden and recent population expansion, which corroborates the studies of Yu-JiaQin et al. (2016) ; Schutze et al. (2012). Depending on the varieties of host plants, the results of the neutrality tests give insignificant tajima's $D$ and Fu's Fs, which reaffirms the hypothesis of a population in equilibrium or in moderate expansion. Neutrality tests and molecular analysis of variance are supported by mismatch distribution curves, which represent the qualitative distribution of genetic distances between individuals in a population taken in pairs of sequences. This distribution is multimodal in the two areas even if the curve of allele frequencies in pairs observed is not superimposed on the curve of the expected frequencies. This suggests that there is a gap between the observed values and the expected values resulting in a population in equilibrium or in moderate expansion. The structure of the haplotype network seems consistent to us compared to the results of neutrality tests. This network reflects a majority ancestral haplotype (H1) composed of seven individuals from two agro-ecological areas belonging to different host plants except mandarin, an intermediate $\mathrm{H} 7$ haplotype linking five other individuals of notto and 19 individual haplotypes. Phylogenetic trees reveal the existence of three clades, which show no grouping according to the varieties of host plants. However, they suggest an area based clustering with clades 3 of the two methods, which consist only of individuals from the Niayes area and from a single sampling site (Notto). In clade 2 of the parsimony method, there is a grouping depending to locality, a clade composed mainly of individuals from the Niayes area with two individuals from Casamance. We also note that almost all of the individuals from the southern area are in the clades 1 with the two methods. This grouping according to areas could be explained by the fact that $B$. dorsalis has a very polyphagous character, multiple hosts and cultivated outside the production season of mangoes such as citrus fruits. This mango seasonality (May to October), makes 
these citrus fruits secondary hosts for $B$. dorsalis. However, $B$. dorsalis has the possibility of multiplying its population throughout the year while awaiting another period of mango production, where which this stable population or in moderate demographic expansion. This expansion could also be explained by the fact that several species of the Tephritidae family are very mobile travellers, they engage in large dispersive movements during the period of search to host plants, mating and maturation, which means that its genetic structure is linked to the locality and not to the host plant. According

\section{CONCLUSION}

This exploratory study carried out as part of the project to support and control the fruit fly at the regional level has provided a great deal of information on the genetic characterization of the species Bactrocera dorsalis, in particular on its structure and genetic differentiation. It brings a better knowledge of the genetic structure of the insect according to agro-ecological areas such as the Niayes area and the lower Casamance, which until now has not been the subject of a research subject in

\section{ACKNOWLEDGMENTS}

We thank the Senegalese Institute for Research Agricoles (ISRA) through the entomology laboratory of the Center for the Development of Horticulture (CDH) for carrying out this study. Our deep gratitude to the ISRA Sangalkam station in particular to the entomology laboratory for the collection of infested fruits and the breeding of flies. Our warm thanks also to Dr Paterne DIATTA (CNRA / Djibélor) for helping us in the field

\section{BIBLIOGRAPHICAL REFERENCES}

Choudhary, JS, Naaz, N., Lemtur, M., Das, B., Singh, AK, Bhatt, BP, Prabhakar, CS, 2018. Genetic analysis of Bactrocera zonata (Diptera: Tephritidae) populations from India based on cox1 and nad1 gene sequences. Mitochondrial DNA Part A 29, 727-736.

Choudhary, JS, Naaz, N., Prabhakar, CS, Lemtur, M., 2016. Genetic analysis of oriental fruit fly, Bactrocera dorsalis (Diptera: Tephritidae) populations based on mitochondrial cox1 and nad1 gene sequences from India and other Asian countries. Genetica 144, 611-623.

Fall AS, Fall ST, Cisse I, Badiane AN, Diao MB, Fall CA. 2001. Characterization of the Niayes area. In CITES Horticoles suspended? Urban Agriculture les Grandes Niayes in Senegal. to Ndiaye et al. (2012) and Ndimanya and Strebelle, (2013) the distribution of the species would be due to the production of mangoes in Senegal which has existed for a long time in traditional form, especially in regions with a vocation for fruit production, in orchards and in planting at the level of family farms as well as small and medium farmers. These orchards, located mostly in the south of the country, with local varieties of host plants not benefiting from irrigation or adequate cultivation techniques, favour the multiplication and dispersal of the species.

Senegal. The results obtained at the end of the research showed a balanced population or a moderate expansion, a high genetic variability and a weak genetic structure linked to the localities. These results open up new avenues for more in-depth studies on the fruit fly in order to identify control alternatives and the favourable period for slowing the dispersal of the Bactrocera dorsalis species.

collection in the South zone, at the Cheikh Anta DIOP University in Dakar through the GENGESPOP team for the realization of molecular studies. This research work was supported by funds from the PLMF project (Support Project for the Regional Plan for the Fight and Control of Fruit Flies in West Africa), the executing agency CORAF that we also wish to address our deep gratitude.

IDRC. Http // idrc.ca / en / ev-27906-201-1 DO_TOPIC.htm.

Gasperi, G., Guglielmino, CR, Malacrida, AR, Milani, R., 1991. Genetic variability and gene flow in geographical populations of Ceratitis capitata (Wied.) (Medfly). Heredity 67, 347.

Grant, WS, Bowen, BW, 1998. Shallow population histories in deep evolutionary lineages of marine fishes: insights from the sardines and anchovies and lessons for conservation. Journal of Heredity 89, 415-426.

Grechi, I., Sane, CAB, Diame, L., De Bon, H., Benneveau, A., Michels, T., Huguenin, V., Malezieux, E., Diarra, K., Rey, J. -Y., 2013. Mango-based orchards in Senegal: diversity of design and management patterns. Fruits 68, 447-466. 
Hendel, F. (1912). H. Sauter's Formosa- Ausbeute. Genus Dacus, Fabricius (1805) (Diptera). Supplementa Entomologica, 1, 13-24.

Holsinger KE (2010). Tajima's D, Fu's FS, Fay and Wu's $\mathrm{H}$,

http://darwin.eeb.uconn.edu/eeb348/lecturenot es/mole vol-tajima.pdf

K Zeng, Y.-X. Fu, S Shi, and C.-I. Wu. Statistical tests for detecting positive selection by utilizing highfrequency variants. Genetics, 174:1431-1439, 2006.

Lopez, P., Casane, D., Philippe, H., 2002. Molecular phylogeny and evolution-Bioinformatics (5). Medicine / science 18, 1146-1154.

Ndiaye A., 2014. Genetic characterization, gene flow evaluation of different ecotypes of the weevil Caryedon serratus (Olivier). (Coleoptera, Chrysomelidae), pest of peanut stocks (Doctoral dissertation in Sciences). Cheikh Anta DIOP University, (Senegal), 118p.

Ndiaye, O., Vayssières, J.-F., Yves Rey, J., Ndiaye, S., Diedhiou, PM, Ba, CT, Diatta, P., 2012. Seasonality and range of fruit fly (Diptera: Tephritidae) host plants in orchards in Niayes and the Thiès Plateau (Senegal). Fruits 67, 311-331. https://doi.org/10.1051/fruits/ 2012024

Norrbom, A. 2004. Fruit Fly (Diptera: Tephritidae) Classification and diversity, Systematic and Entomology Laboratory, ARS, USDA, Department of entomology, NMNH, SI; The Diptera Site.

Onah, IE, Eyo, JE, Taylor, D., 2017. Application of PCRRFLP of COI Gene for Identification of Life Stages of Bactrocera dorsalis and Ceratitis anomie Infesting Citrus in Southeastern Nigeria. African Entomology 25, 485-493. https://doi.org/10.4001/003.025.0485

Qin, Y., Krosch, MN, Schutze, MK, Wang, X., Prabhakar, CS, Susanto, A., Li, Z. (2018). Population structure of a global agricultural pest, Bactrocera dorsalis (Diptera: Tephritidae). Evolutionary Applications, 11, 1990-2003.

Schutze, MK, Krosch, MN, Armstrong, KF, Chapman, TA, Englezou , A., Chomič , A., Cameron, SL, Hailstones, D., Clarke, AR, 2012. Population structure of Bactrocera dorsalis ss, B. papayae and B. philippinensis (Diptera: Tephritidae) in southeast Asia: evidence for a single species hypothesis using mitochondrial DNA and wingshape data. BMC Evolutionary Biology 12, 130.
Sembène M., 2000. Variability of spacer Internal Transcribed (ITS) of the ribosomal DNA locus and polymorphism of microsatellites in the weevil Caryedon serratus (Olivier): diff e rentiation into races $h$ oh your infestation and the ' peanut Senegal. (The doctoral thesis of ' State Science). University Cheikh Anta Diop, (Senegal), 180p.

Shi, W., Kerdelhue, C., Ye, H., 2012. Genetic structure and inferences on potential source areas for Bactrocera dorsalis (Hendel) based on mitochondrial and microsatellite markers. PLoS One 7, e37083.

Vayssières, J.-F., Sanogo, F., Noussourou, M., 2004. Inventory of fruit fly species (Diptera: Tephritidae) subservient to the mango tree in Mali and controlled control trials. Fruits 59, 316.

Yu- JiaQin , Nopparat Buahom , Matthew N. Krosch , Yu Du4, YiWu , Anna R. Malacrida , Yu- Liang Deng, Jia -Qi Liu, Xiao-Long Jiang4, Zhi -Hong $\mathrm{Li}, 2016$. Genetic diversity and population structure in Bactrocera correcta (Diptera: Tephritidae) inferred from mtDNA cox1 and microsatellite markers 10. https://doi.org/10.1038/srep3846 and bionomics. CAB International, Wallingford, United Kingdom, 601 pp cucurbitae in West and Central Africa. Fruits 62, 391-39 